\title{
A Step Towards Electric Propulsion Testing Standards: Pressure Measurements and Effective Pumping Speeds
}

\author{
John W. Dankanich ${ }^{1}$ \\ AeroDank, Inc., Cleveland, OH, 44135 \\ and \\ Michael W. Swiatek ${ }^{2}$ and John T. Yim ${ }^{3}$ \\ NASA Glenn Research Center, Cleveland, $\mathrm{OH}, 44135$
}

\begin{abstract}
The electric propulsion community has been implored to establish and implement a set of universally applicable test standards during the research, development, and qualification of electric propulsion systems. Existing practices are fallible and result in testing variations which leads to suspicious results, large margins in application, or aversion to mission infusion. Performance measurements and life testing under appropriate conditions can be costly and lengthy. Measurement practices must be consistent, accurate, and repeatable. Additionally, the measurements must be universally transportable across facilities throughout the development, qualification, spacecraft integration and on-orbit performance. A preliminary step to progress towards universally applicable testing standards is outlined for facility pressure measurements and effective pumping speed calculations. The standard has been applied to multiple facilities at the NASA Glenn Research Center. Test results and analyses of universality of measurements are presented herein.
\end{abstract}

\section{Nomenclature}

a $\quad=$ Clausing Transmission Coefficient

A $=$ Cross-sectional Area, $\mathrm{cm}^{2}$

$\mathrm{C}=$ Conductance, $\mathrm{L} / \mathrm{s}$

$\mathrm{C}_{\text {Subscript }}=$ Conductance of the Element, $\mathrm{L} / \mathrm{s}$

$\mathrm{C}_{\mathrm{M}}=$ Molecular Conductance

$\mathrm{D} \quad=$ Diameter, $\mathrm{m}$

$\mathrm{I}_{\mathrm{R}} \quad=$ Molecular Impact Rate

$\mathrm{I}_{\mathrm{S}} \quad=$ Molecular Impacts with a Surface, atoms $/ \mathrm{cm}^{2}-\mathrm{s}$

$\mathrm{k}=$ Pumping speed reduction factor

$\mathrm{L}=$ Length, $\mathrm{m}$

$\mathrm{M}=$ Molecular Weight

$\mathrm{n} \quad=$ Number of Moles

$\mathrm{P} \quad=$ Pressure, Torr

$\mathrm{P}_{\mathrm{B}} \quad=$ Base Pressure, Torr

$\mathrm{P}_{\mathrm{Eff}} \quad=$ Effective Pumping Speed, L/s

$\mathrm{P}_{\mathrm{Eq}} \quad=$ Equivalent Pumping Speed, $\mathrm{L} / \mathrm{s}$

$\mathrm{P}_{\mathrm{S}} \quad=$ ISO Rated Pumping Speed, L/s

$\mathrm{R}=$ Ideal Gas Constant, $0.08206 \mathrm{~L}$ atm $/$ mole $\mathrm{K}$

$\mathrm{T}=$ Temperature, $\mathrm{K}$

$\mathrm{V}=$ Volumetric Flow Rate, $\mathrm{L} / \mathrm{cm}^{2}-\mathrm{s}$

\footnotetext{
${ }^{1}$ Lead Systems Engineer, NASA's ISPT Program, 21000 Brookpark Road, M/S 142-5, AIAA Senior Member.

${ }_{3}^{2}$ Experimental Facilities Technician, Glenn Research Center Facilities Division.

${ }^{3}$ Aerospace Engineer, Space Propulsion Branch, AIAA Member.
} 


\section{Introduction}

$\mathrm{T}$ he acknowledgement of challenges associated with accurate, consistent, repeatable, and transportable test results of electric propulsion (EP) systems has been well documented in recent years. ${ }^{1}$ As such, there has been significant interest in developing rigorous standards for electric propulsion testing from both internal and external communities. Several community efforts including the European Space Agency (ESA), the Joint Army Navy NASA Air Force (JANNAF) Task on Plasma Diagnostics, and the American Institute of Aeronautics and Astronautics (AIAA) have begun efforts to "standardize" practices and measurements during the testing of electric propulsion devices. The electric propulsion testing literature has a multitude of examples of poor test practices. A single device is often tested at multiple facilities under inconsistent operating conditions using variations in diagnostics. Multiple suppliers with unique facilities and processes can exacerbate the issue. Several institutions have preferred diagnostic designs, calibration methods, and data reduction methodology. Multiple diagnostic designs are acceptable; provided sufficient information is obtained and provided to reduce the data into a transportable result. It is desired to have standardized testing with repeatable and transportable results from data collected at research facilities through final spacecraft integration testing. The AIAA effort is an attempt to coordinate an acceptable and documented set of standards, guides, and best practices for electric propulsion testing open to the community. ESA completed a draft handbook for electric propulsion testing in February $2012^{2}$ and AIAA began their effort in March. Both are expected to produce evolvable guidelines towards the goal of standardized test practices. One piece of the larger effort is addressing facility pressure measurements and sufficiently mitigating or at least quantifying facility effects. A preliminary methodology of measuring facility pressure and calculating effecting pumping speed is presented.

\section{Pressure Measurement / Effect Pumping Speed Standardization}

Facility effects continue to be an area of interest to the electric propulsion community. Maintaining sufficiently low facility pressures continues to drive facility requirements as high power systems are employed using noncondensable propellants. Experimental and theoretical efforts have been completed to quantify the influence of ground facility pressure on global performance characteristics and oscillatory behavior. Additional recent studies have exposed more complex pressure-thruster interactions. Ultimately, a methodology is desired to correlate and discern sources of variations between ground and flight environments.

\section{A. Common Practices and Historical Evidence}

As noted in a review on facility effects, the practice of specifying the pressure measurement can vary widely from whether or not gauge location is noted, what gauge sensitivity factor is used, if the gauges are shielded, the type of gauge used, or even the averaging gauges of different locations. ${ }^{3}$ The EP community has not historically employed standards regarding pressure gauge calibrations and in some cases could have discrepancies of a factor of two. These practices support the need for experimental and analytical test standards for pressure measurements.

Another misleading practice throughout the community is the specification of a facilities pumping speed capability without discussion of practical effective pumping speed. The NASA Glenn Research Center (GRC) states a capability of 3,500,000 1/s (air) for VF-5, Arnold Engineering Development Center (AEDC) claims a conservative estimate of 5,000,000 1/s (Xe) for their 12V facility, and University of Michigan Large Vacuum Test Facility claims seven cryopumps have a combined pumping speed of 500,000 1/s (Air) / 240,0001/s (Xe). The relevant effective pumping speeds are expected to be lower. As example, the maximum orifice conductance of xenon is $5.451 / \mathrm{s} / \mathrm{cm}^{2}$ $\left(35.2 \mathrm{l} / \mathrm{s} / \mathrm{in}^{2}\right)$. Therefore a $12 \mathrm{ft}$ diameter chamber has a maximum conductance of only $573,300 \mathrm{l} / \mathrm{s}$.

\section{B. Required Effective Pumping Speeds}

One of the driving facility requirements for electric propulsion testing is that pressures are sufficiently low to obtain reliable data. Facility effects impact various measurements differently. Performance is primarily affected by ingested propellant background gas; which can be difficult to estimate due to "beam pumping" effects. Lifetime is primarily affected by the changes in the ion fluxes that cause erosion of the various thruster surfaces. Far-field plume measurements are most sensitive by plasma densities and energies caused by the facility environment. Early testing of the Stationary Plasma Thruster (SPT)-100 provided guidance regarding acceptable facilities pressures requires for performance, lifetime and near-field plume measurements; $5 \times 10^{-5}$ torr, $5 \times 10^{-6}$ torr, and $1.3 \times 10^{-5}$ torr respectively. ${ }^{4,5}$ The authors note that this accepted standard for Hall Effect Thrusters (HETs) does not include any specifications regarding pressure measurement methodology, locations, or correction factors.

Extremely low levels of contaminants can have profound effects on measured lifetimes. Nitrogen and air can interact with surfaces and drastically change their sputter rates. Also, there is limited data on background partial 
pressures. For gridded ion engines, it has been observed that breakdown rates of ion thruster begins to be affected in the low $10^{-5}$ torr range and lifetime measurements may be impacted at 5 $\times 10^{-7}$ torr. $^{6}$ However, with the NASA Solar Technology Application Readiness (NSTAR) life test conducted at $4 \times 10^{-6}$ torr and nominal flight mission performance; it is likely to become the accepted standard for life testing of gridded-ion engines. ${ }^{7}$ NASA's Evolutionary Xenon Thruster (NEXT) Long Duration Test has been conducted at a maximum pressure of $2.5 \times 10^{-6}$ torr $^{8}$ and the BPT-4000 Life Test was conducted at $2.5 \times 10^{-5}$ torr $^{9}$. Figure 1 illustrates the required effective pumping necessary to meet the specified pressure measurements for a 2000s HET operating at $55 \%$ efficiency based on the SPT-100 guidelines noted earlier.

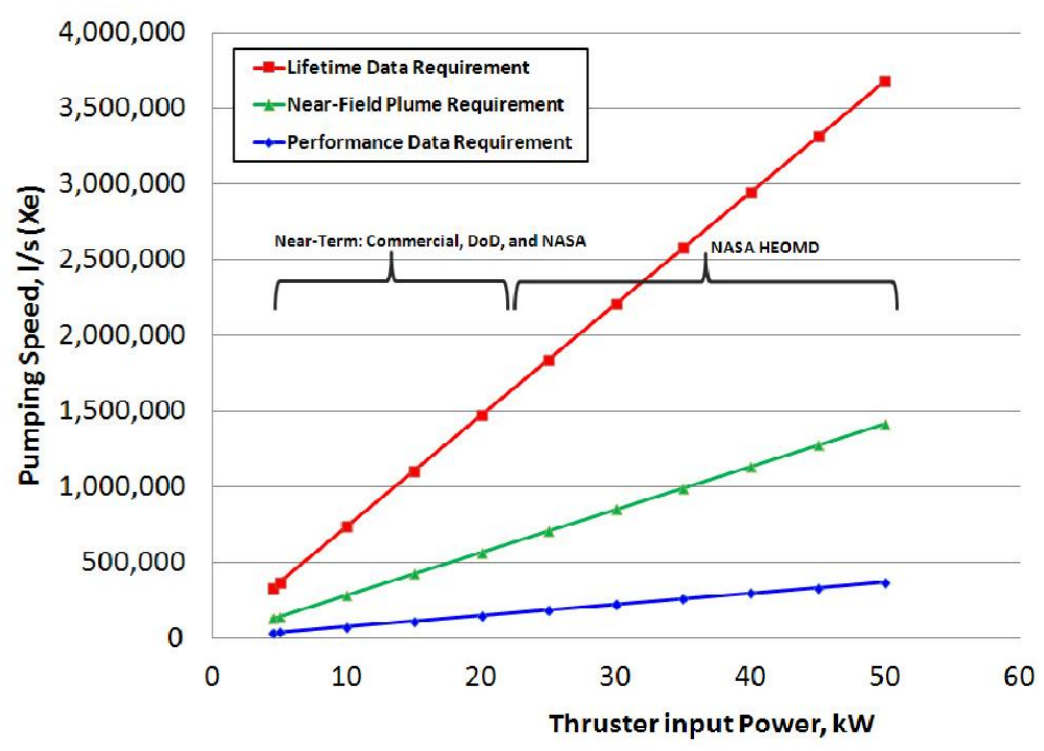

Figure 1. Effective pumping speeds required for reliable test results.

\section{Pressure Measurements Diagnostics}

The community has several instruments available for making pressure measurements during electric propulsion testing. The pressure diagnostics most commonly used include the spinning rotor gauge, cold-cathode gauges and hot-cathode gauges.

\section{A. Spinning Rotor Gauge}

The spinning rotor gauge (SRG) is well established as a standard for transitional vacuum pressure measurements. An SRG operates through the magnetic levitation of a stainless steel ball. The ball is suspended and spun up to a specified spin rate and then allowed to spin freely. Collisions of gas molecules with the surface of the ball create drag to decelerate the ball. This deceleration is measured and the pressure is derived. Spinning rotor gauges have better than $1 \%$ precision down to $5 \times 10^{-7}$ torr. Also, since the SRG measurement is mechanical, no thermal or ionization effects influence the accuracy of the measurements. The calibration is weakly dependent on the ball's surface roughness, so the SRG is a stable reference standard; better than $1 \%$ variance per year. It is not recommended to use an SRG where the system may become coated with sputtered material. Therefore an SRG is not recommended as the baseline for in-situ pressure measurements during thruster testing.

\section{B. Cold Cathode Gauge}

Cold cathode gauges (CCG) operate with a "cold" discharge. They are applicable over a range of $10^{-2}$ and $10^{-9}$ torr. Rather than a heated filament, they contain two unheated electrodes and the discharge is excited with a DC voltage $\sim 2 \mathrm{kV}$. The gauge uses a magnetic field to constrain the electron path such that it has sufficient collision probability with the gas for measurement; the electrons are confined to spiral and oscillate between two cathode plates. Positive and negative charge carriers produced by collision move to the corresponding electrodes and form a pressure-dependent discharge current. Cold cathode gauges can measure at higher pressures than a hot-cathode, but is less reliable in the ultra high vacuum range. Cold cathode gauges have accuracies of $+/-50 \%$ in the range of interest for EP testing. Electronics required to operate CCGs are usually simpler and lower cost. Overall, CCGs are not recommended for electric propulsion testing pressure measurement due to their high inaccuracies.

\section{Bayard-Alpert Type Ionization Gauge (Hot Cathode)}

The Bayard-Alpert (BA) Type Ionization Gauge has been the most widely used pressure gauge during electric propulsion testing. The pressure indication of a BA gauge, also known as a hot cathode gauge, is based on the ionization of gas molecules by a constant flow of electrons. Electrons are emitted from a heated cathode and accelerated to a positively charge wire grid. Electrons pass into the space between the grid and a collector wire at 
ground. Electron collisions with gas molecules produce positive ions. The positive ions are collected by the grounded collector wire. The rate that positive ions are formed is directly proportional to the density of molecules. The strength of the ion current is then indicated on a micro ammeter that is calibrated in used of pressure. The hotcathode BA gauge is generally considered the most accurate continuous indicator for pressure below $10^{-3}$ torr. There are various types of BA gauges, included nude gauges and tubulated. Vendors specify typical accuracies of $+/-20 \%$, but $30-50 \%$ total uncertainty has been historically demonstrated. A study on long-term stability (580 days) of BA gauges observed changed in calibration that ranged from $-57 \%$ to $72 \% .{ }^{10}$ Follow-on studies highlighted the influence of the controller on uncertainty, and with a quality controller and proper calibration procedures, accuracies of $+/-20 \%$ can be achieved.

The repeatability, short and long term stability, and gauge-to-gauge reproducibility of glass tubulated gauges are the subject of many studies. Gauge-to-gauge sensitivity with $25 \%$ accuracy at midrange is considered good even with new, unused tubes. Precious metal coatings will improve repeatability. With uncoated glass, it is impossible to control the potential of internal surfaces for reduced measurement accuracy and repeatability. Long-term stability is affected by changes in the electrode structure, particularly after thermal cycling.

Preferred mounting orientation is with the filament and anode grid in a vertical position to minimize the electrode distortion caused by gravity pull and thermal cycles. Gauges with opposed tungsten filaments have better long-term stability; factor of two. One must also provide conductance connection between the gauge and the vacuum system, glass envelope gauge with 1" tubulation is recommended. One should use all-metal if there will be helium leak testing; due to the heated glass permeation of helium.

Nude gauges are more expensive, and gauge-to-gauge reproducibility is worse with nude gauges; accuracies better than 30\% should not be expected. Repeatability is improved in the absence of the insulated glass envelope.

Nude ion gauges are also affected by the way they are mounted. A study showed that as the dimensions or shape of the gauge's metal envelope are changed; there can be a factor of two impact on the absolute magnitude of the gauge's sensitivity. The envelope must be considered an integral part in the ionization gauge when specifying sensitivity. In practice, nude ion gauges must be calibrated in situ.

\section{Stabil-Ion Gauge (Subset of Hot Cathode)}

Due to the known limitations with respect to stability, accuracy, and reliability of older BA gauges at the pressures of interest, there has been advancement in the gauge technology. One such option is the Stabil-Ion gauge (SIG). The SIG design, shown in Fig. 2, includes dual, independent, thoria-coated, ribbon filaments carefully positioned relative to the anode axis and maintained in tension by refractory metal springs. The filaments exhibit negligible bow, sag, or twist with use, assuring stable and reproducible electron trajectories over time. Partial endcaps are used to extend the radial electric field over a larger area of the anode grid while short filaments are used to introduce electronics away from the regions of the anode, assuring stable ion production conditions with the ionizer. The end-capped anode is precision assembled and stressrelieved so that it maintains its exact shape and position even after high temperature degassing. Electrode positions relative to the walls are identical from gauge-to-gauge for reproducibility. A grounded conductive shield completely surrounds the anode-cathode structure to provide a stable electric environment. The shield is designed to remain dimensionally stable from gauge-to-gauge within close tolerances. A grounded perforated high conductance shield over the port electrically isolates the electrode structures from the rest of the vacuum system. Vendors specify accuracy with air better than $+/-4 \%$ and repeatability $+/-$ $3 \%$. Testing has indicated an uncalibrated accuracy of $6 \%$ and if calibrated on xenon, better than $3 \%$ accuracy. However, measurement must be made with a quality controller; as they are known to contribute up to $+/-15 \%$ inaccuracies. The improved accuracy, gauge-to-gauge consistency, and long-term stability have lead to the

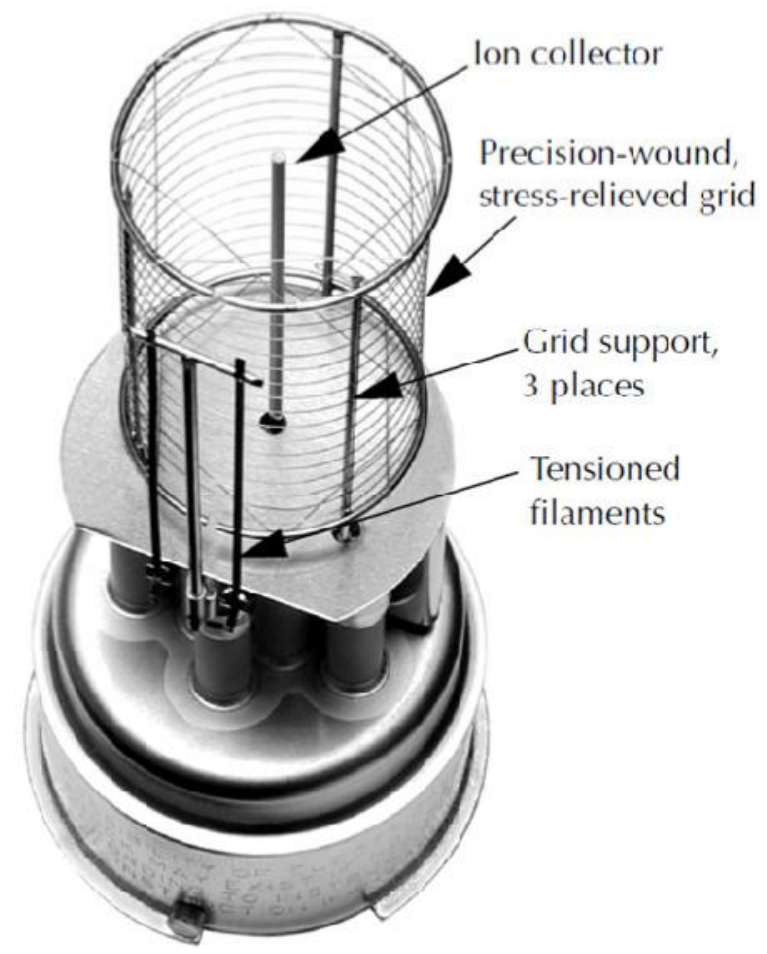

Figure 2. Stabil-Ion gauge. 
author's recommendation to use the Stabil-Ion gauge with high quality controller for future pressure testing.

\section{E. Operation in Presence of a Plasma}

During electric propulsion testing, the pressure gauge may be in the presence of ions. The principle of operation for the hot-cathode gauge, measuring ion collection, would also detect ions from the electric propulsion device; leading to flawed data with high uncertainty in the measurements. A method to use hotcathode gauges in the presence of ions has been demonstrated previously through the use of a ground neutralizing screen in front of the gauge. ${ }^{11}$ An example schematic or the neutralizing scheme with a BA ionization gauge is shown in Fig. 3. A screen should be

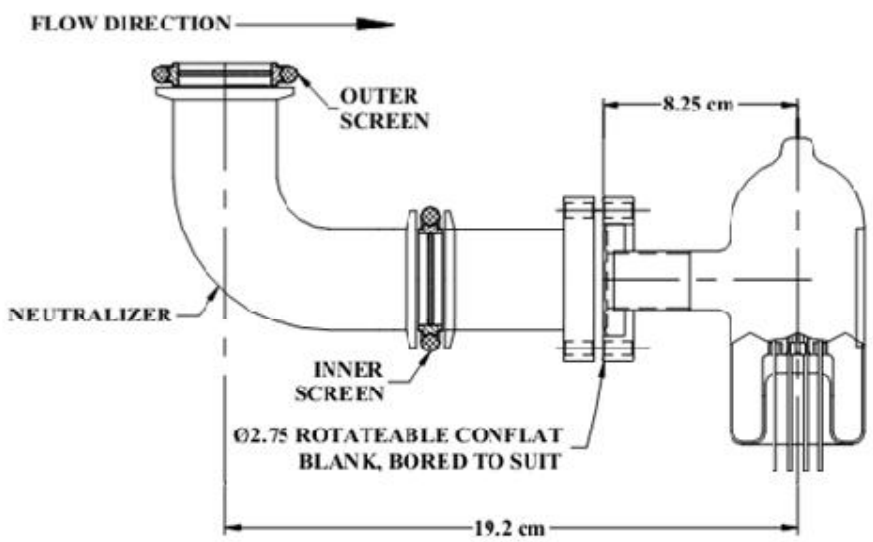

Figure 3. Example neutralizer method demonstrated by Walker. ${ }^{11}$ attached to both ends of the neutralizer. The screens spacing should be sized smaller than five Debye lengths for the sheath to merge and eliminate potential openings for the ions to pass. ${ }^{12}$ This method includes the use of a neutralizer that can prevent line-of-site between the source and the gauge and also be grounded to provide a method of neutralization of discharge ions. It is recommended to use this method when the pressure gauge will be used in the presence of ions. Also, it is required to ascertain any impact the neutralizer may have on the conductance, and therefore measurement, of pressure by the gauge.

\section{F. Calibration and Gauge Conditioning}

The National Institute of Standards and Technology (NIST) calibration for high vacuum (as low as $10^{-9}$ Torr), uses a known gas that flows into the top of a vacuum chamber, passes through an orifice in the middle, and exits at the bottom. Kinetic theory allows the conductance of the orifice to be calculated from its known diameter, which in turn allows the pressure drop to be calculated accurately from the conductance and flow rate. ${ }^{13}$ Gauges should be calibrated to a NIST standard with the controller electronics, feedthroughs and cabling, and gauge in the configuration to be used at least once every six months. Calibration should also be performed on xenon, if xenon will be the primary gas used during testing.

\section{Example Cases and Application}

The methodology for transportable measurements of pressure and effective pumping speed is under preliminary formulation. The methodology has shown reasonably close agreement to historical test data, however; historical data is obtained with limited knowledge of gauge calibration. To validate the method, a series of tests are planned at multiple facilities with various geometries, pump configurations, pump types, and with and without cryopanels. Results for initial validation testing using NASA GRC's VF-7 is provided below.

\section{A. Facility Description}

NASA GRC's VF-7 is a 10'

Diameter x 15' Length Facility with a historical base pressure of $1 \times 10^{-7}$ torr and rated with a nominal pumping speed of $125,000 \mathrm{~L} / \mathrm{s}$ (air) using five 32" Oil Diffusion Pumps (ODPs). The facility schematic, pump and gauge locations are illustrated in Fig. 4. For calculations, the radius of the facility is 59.5 inches for an area of $11,122 \mathrm{in}^{2}$

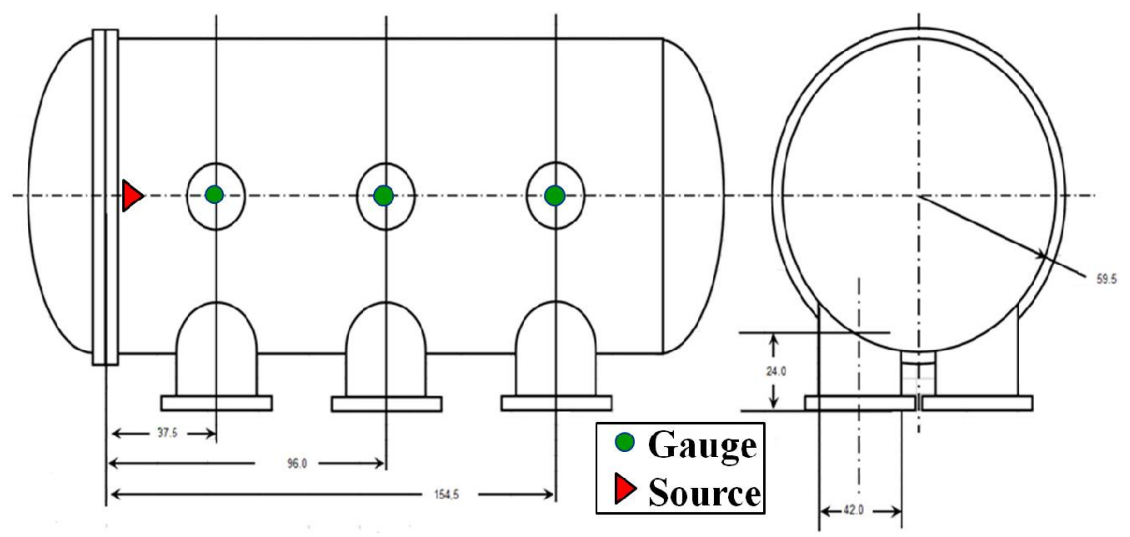

Figure 4. VF-7 schematic. 
$\left(71,754.8 \mathrm{~cm}^{2}\right)$. The length of the facility is $118 \mathrm{in}$ with ODP 1 , ODPs 2 and 3, and ODPs 4 and 5 located at $37.5 \mathrm{in}$, 96in, and $154.5 \mathrm{in}$ respectively. The three pressure gauges are also located at $37.5 \mathrm{in}, 96 \mathrm{in}$, and $154.5 \mathrm{in}$. All measurements are from the end cap flange face.

\section{B. Effective Pumping Speed Calculations}

The rated pumping speeds of the ODPs provide very little insight into the actual performance capability of the facility. The parameter that is of primary concern is the conductance of the chamber. Most facilities of interest have a cylindrical shell design. Calculations for conductance in a pipe are straightforward and often used. However, the pipe equation yields its best accuracy when the length-to-diameter (L/D) ratio is greater than 10 while most facilities have L/D ratios less than 5 . To accommodate this lower ratio, it is recommended to calculate aperture conductance and then applying the Clausing Transmission Coefficient for the length-to-diameter component. Molecular conductance is provided in Eq. (1). Clausing Transmission Coefficients are dependent on the length-to-radius ratio, as shown in Fig. 5.

$$
\mathrm{C}_{\mathrm{M}}=\mathrm{I}_{\mathrm{R}} * \mathrm{a} * \mathrm{~A}
$$

The flow rate across the aperture is dependent on gas species since molecular velocities are dependent on molecular weight. A molecular impact rate is established for specific gas species.

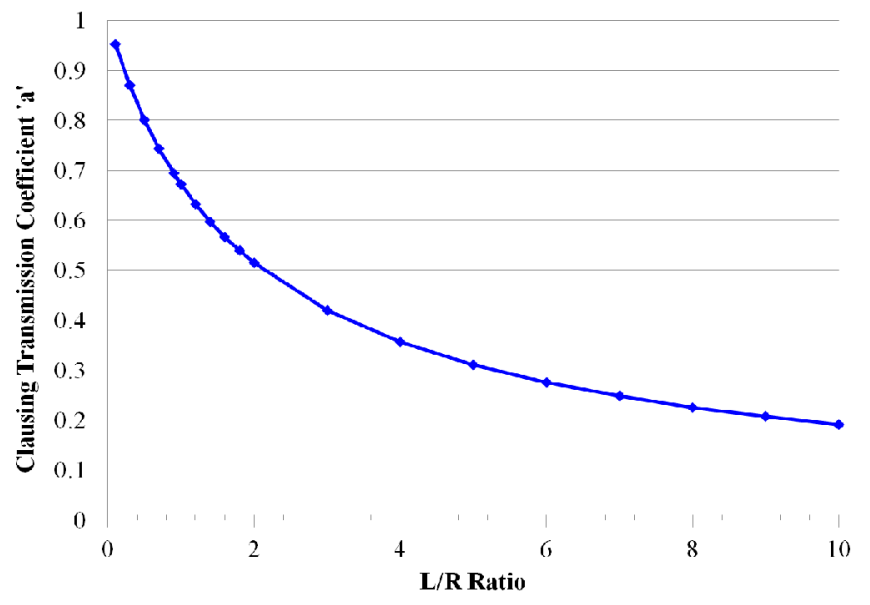

Figure 5. Clausing transmission coefficients.

Calculations included here are for air and xenon since they are the most relevant to provided pump data and standard Hall and gridded-ion operation respectively. The base pressure used is dependent on the base pressure of the particular chamber recorded during testing.

A typical ODP installation will have a circular extension / nozzle extending from the main vessel terminating with a flange for bolting. The conductance for this nozzle will determine the delivered pumping capability to the main chamber. As required by ISO Standard 1608, the gauge tube is mounted at D/2 above the connecting flange of the pump, and for AVS 4.1, the mounting distance is $\mathrm{D} / 4$. The gauge location dimension will be subtracted from the overall length of the nozzle when calculating the conductance.

The nozzle extension also houses a chevron baffle directly above the ODP, or in some cases the chevron is bolted directly to the ODP. If the conductance of the chevron is provided by the manufacturer, then the pumping speed at the chevron outlet can be found using Eq. (2).

$$
1 / \mathrm{P}_{\mathrm{Eff}}=1 / \mathrm{P}_{\mathrm{S}}+1 / \mathrm{C}_{\text {Baffle }}
$$

Because the baffle is not mounted at the gauge distances listed in either ISO 1608 or AVS 4.1, an equivalent pump speed at the opening of the pump is necessary for the calculation. Again, we use the Clausing Transmission Coefficient to find the equivalent pump speed. For $\mathrm{D} / 2(\mathrm{R})$ and $\mathrm{D} / 4(\mathrm{R} / 2)$, the coefficients are 0.671984 and 0.801271 respectively. For VF-7, the ISO pumping speeds are rated for air at 23,000 1/s mounted according to ISO 1608 , therefore the equivalent speed at the pump entrance is give by Eq. (3).

$$
\mathrm{P}_{\mathrm{Eq}}=\mathrm{P}_{\mathrm{S}} / \mathrm{a}=(23,000 \mathrm{~L} / \mathrm{s}) / 0.671984=34,227 \mathrm{~L} / \mathrm{s}
$$

It is also common practice for the baffle manufacturers to provide a pumping speed reduction factor, $\mathrm{k}$. For VF7 , the chevron manufacturer provided a correction factor of $50 \%$. This can be used to determine the conductance of the baffle.

$$
\begin{gathered}
\mathrm{P}_{\mathrm{Eff}}=\mathrm{k}^{*} \mathrm{P}_{\mathrm{Eq}} \\
1 /\left(\mathrm{k}^{*} \mathrm{P}_{\mathrm{Eq}}\right)=1 / \mathrm{P}_{\mathrm{Eq}}+1 / \mathrm{C}_{\text {Baffle }}
\end{gathered}
$$

Therefore: 


$$
\mathrm{C}_{\mathrm{Baffle}}=\mathrm{k}^{*} \mathrm{P}_{\mathrm{Eq}} /(1-\mathrm{k})
$$

For the chevron,

$$
\mathrm{C}_{\text {Chevron }}=0.5 * 34,227 \mathrm{~L} / \mathrm{s} /(1-0.5)=34,227 \text { liters } / \mathrm{sec} \text { (air) }
$$

The halo baffle manufacturer provides a correction factor of $60 \%$.

For the halo baffle,

$$
\mathrm{C}_{\text {Baffle }}=0.6 * 34,227 \mathrm{~L} / \mathrm{s} /(1-0.6)=51,341 \text { liters } / \mathrm{sec} \text { (air) }
$$

The example chamber has a 24in nozzle length and a 42in nozzle diameter; yielding a Clausing coefficient of 0.643587. The conductance of the nozzle is given by Eq. (9).

$$
\mathrm{C}_{\text {Nozzle }}=\mathrm{V} * \mathrm{~A} * \mathrm{a}
$$

The volumetric flow rate can be found using the perfect gas equation and surface impact calculations provided in Eqs. (10) and (11) respectively.

$$
\begin{gathered}
\mathrm{PV}=\mathrm{nRT} \\
\mathrm{I}_{\mathrm{S}}=3.5 \times 10^{22} * \mathrm{P} /(\mathrm{M} * \mathrm{~T})^{1 / 2}
\end{gathered}
$$

Assuming a temperature of $293 \mathrm{~K}, \mathrm{M}$ for air and xenon as 28.96 and 131.29 respectively, and the measured base pressure of $3 \times 10^{-7}$ torr:

$$
\begin{aligned}
& \mathrm{I}_{\mathrm{S}}(\text { Air })=3.5 \times 10^{22} * 3 \times 10^{-7} /(28.96 * 293)^{1 / 2}=1.1399 \times 10^{14} \text { atoms } /\left(\mathrm{cm}^{2} \mathrm{~s}\right) \\
& \mathrm{I}_{\mathrm{S}}(\mathrm{Xe})=3.5 \times 10^{22} * 3 \times 10^{-7} /(131.29 * 293)^{1 / 2}=5.3535 \times 10^{13} \text { atoms } /\left(\mathrm{cm}^{2} \mathrm{~s}\right)
\end{aligned}
$$

Then using Eq. (14);

Yielding:

$$
\mathrm{V}=\left(\mathrm{I}_{\mathrm{S}} / 6.022 \mathrm{E} 23\right) * \mathrm{R} * \mathrm{~T} / \mathrm{P}
$$

$$
\mathrm{V}=11.529 \mathrm{~L} / \mathrm{cm}^{2} \mathrm{~s} \text { (Air) and } 5.415 \mathrm{~L} / \mathrm{cm}^{2} \mathrm{~s}(\mathrm{Xe})
$$

Finally, substituting into Eq. (9) for Xe:

$$
\mathrm{C}_{\text {Nozzle }}=11.529 * 8938 * 0.643587=66,322 \mathrm{l} / \mathrm{s}(\text { Air) }
$$

The system conductance for the single ODP at the vessel entrance is:

Therefore:

$$
1 / \mathrm{C}_{\text {Total }}=1 / \mathrm{C}_{\text {Chevron }}+1 / \mathrm{C}_{\text {Baffle }}+1 / \mathrm{C}_{\text {Nozzle }}
$$

$$
\mathrm{C}_{\text {Total }}=1 /(1 / 51,341+1 / 34227+1 / 66337)=15,6811 / \mathrm{s} \text { (Air) }
$$

Using the effective pumping speed and nozzle conductance, the pumping speed at the entrance to the chamber can be calculated as:

$$
1 / \mathrm{P}_{\text {Entrance }}=1 / \mathrm{P}_{\mathrm{Eff}}+1 / \mathrm{C}_{\text {Total }}
$$

Therefore;

$$
\mathrm{P}_{\text {Entrance }}=10,754 \mathrm{~L} / \mathrm{s} \text { (Air) and 5,058 liters /sec (Xe) }
$$

From these calculations, we can predict what gauges should read from various locations in the chamber using superposition of each of the pumps individual speeds with respect to the conductance calculated for the distance to the pump. Assume the thruster is located $50 \mathrm{~cm}(\sim 20 \mathrm{in})$ from the endcap and thrusting into the chamber at a location before the plane of the first pumping surface, as is often the case. The distances from pump 1, pumps 2 and 3 , and pumps 4 and 5 in combination with the radius of the facility provide the Clausing coefficients of $0.87,0.62$, and 0.48 
respectively. Equation 1 is then applied to calculate the conductance and then finally effective pumping from each of the pumps and summed for the total effective pumping speed as shown in Eqs. (21)-(24).

$$
\begin{gathered}
\mathrm{P}_{\text {Eff }}\left(\text { Pump 1) }=1 /\left(1 / \mathrm{C}+1 / \mathrm{P}_{\text {Entrance }}\right)=1 /(1 / 338,121+1 / 5,058)=4,984 \text { liters } / \mathrm{sec}\right. \\
\mathrm{P}_{\text {Eff }}(\text { Pump } 2)=1 /(1 / 239,859+1 / 10,117)=9,707 \text { liters } / \mathrm{sec} \\
\mathrm{P}_{\text {Eff }}(\text { Pump } 3)=1 /(1 / 188,338+1 / 10,117)=9,601 \text { liters } / \mathrm{sec}
\end{gathered}
$$

Then by superposition:

$$
\mathrm{P}_{\text {Total }}=24,292 \text { liters } / \mathrm{sec}(\mathrm{Xe})
$$

Note than $\mathrm{P}_{\text {Total }}$ is significantly different than the stated pumping capability of the facility, by more than a factor

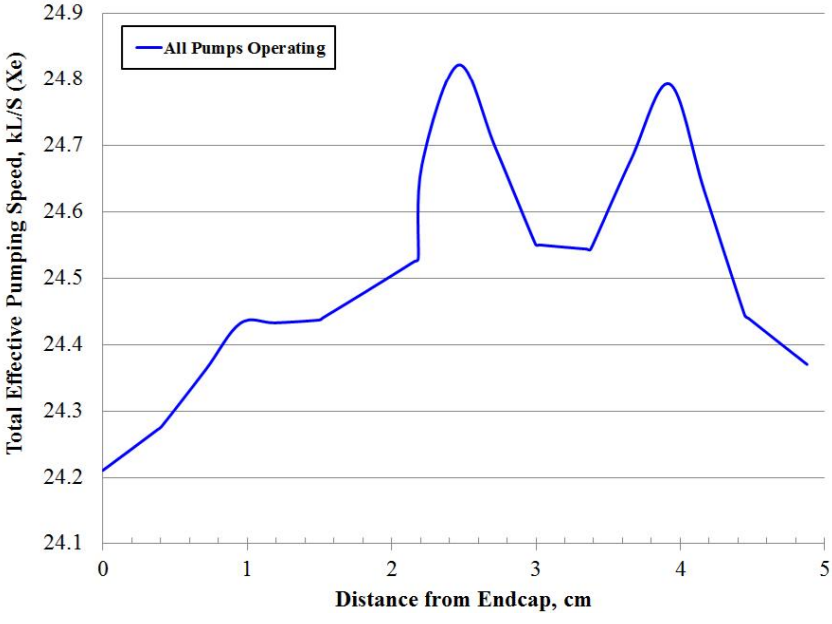

Figure 6. Effective pumping speed example.

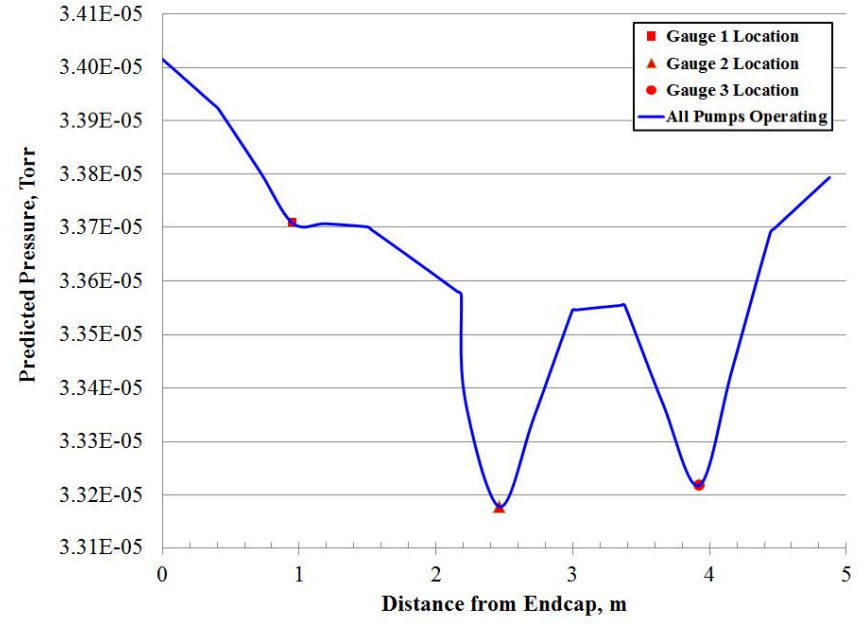

Figure 7. Pressure measurements expected at $65 \mathrm{sccm}$.

of 2. This methodology can be applied to calculate the effective pumping speed from anywhere in the chamber. A plot of effective pumping speed throughout the facility is shown in Fig. 6. Also, after measuring the base pressure, the expected gauge readings from anywhere in the facility, at a specified flow, rate are illustrated in Fig. 7. Figures 6 and 7 assume pressure is measured at the location of the source. A pressure gauge located downstream of the thruster will provide measurements giving little direct insight into the pressure and effective pumping speed at the location of the thruster.

While the eventual end-state may be for all electric propulsion facilities to have a facility model or combined thruster-facility simulation tool, the above demonstrates a simplified methodology for uniform reporting of measurements relevant to the community.

\section{Early Validation Results}

To validate the results, testing is initially planned for NASA GRC facilities VF-5, VF-7, VF-12, and VF-8. The range of facilities is to include only ODPs, cryo-pumping, and a range of $\mathrm{L} / \mathrm{D}$ ratios and configurations. Both cold flow and hot-fire testing is planned. Initial cold flow results are shown in Fig. 8 with a cold flow source and three pressure gauges placed at three downstream locations. VF-5 was operated in three separate configurations, with all pumps operating, only the back-two operating, and only the front 3 ,

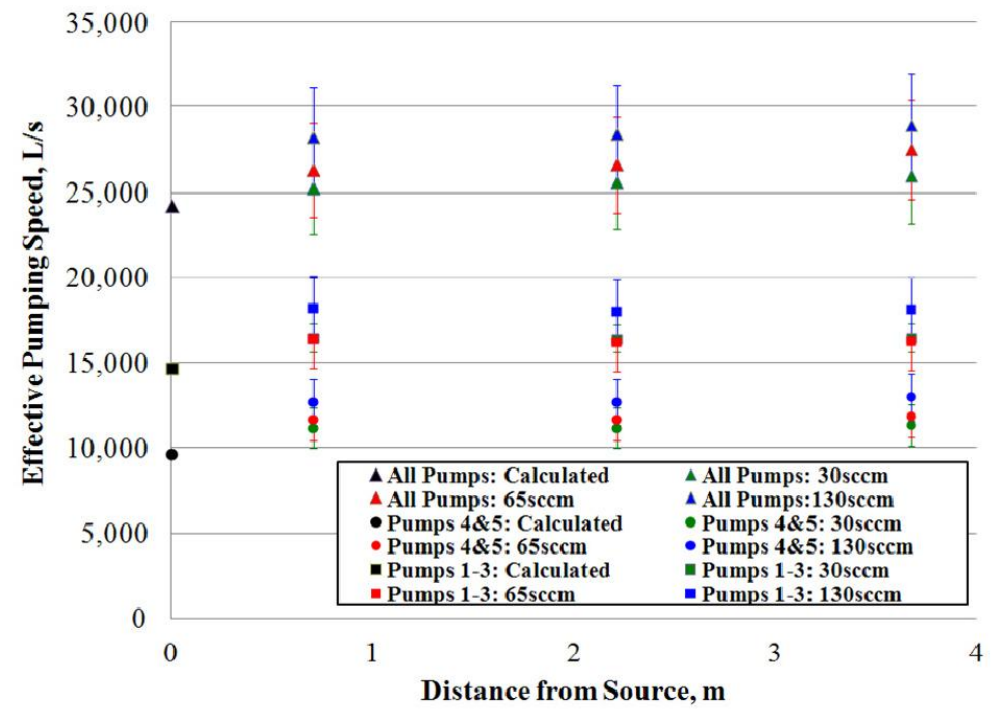

Figure 8. Measured pumping speeds. 
refer back to Fig.4. The results indicate that the gauges far down stream of the source are not sufficient for pumping speed measurements without correlating them to a reference point. Even with the uncertainty analses, the pressure gauges downstream, especially at higher flow rates, over-preduct the effective pumping speed at the source location if used as a direct measurement. Note that with if a standard BA gauge, the error bars would be too large to differentiate if the downstream measurements are sufficient. The importance of having a gauge near the exit plane of the thruster is more critical for facilities with larger pumping capability gradients.

\section{Practical Application}

The NASA Glenn VF-5 chamber is one of the premier electric propulsion test facilities in the world. Officially, the capability is quoted as 3,500,000 L/s of cryo-pumping and an additional 250,000 L/s capability from twenty 32 inch ODPs and cold traps on air. ${ }^{14}$ This capability is quoted regardless of thruster location, location of the cryopanels, or conductance within the facility. For several tests completed in VF-5, thrusters have been placed in the bell jar on the end and slid forward into the VF-5 primary vessel. Additionally, tests can be performed with the thruster placed in the main chamber farther forward from the bell jar. In addition to the two thruster locations, with the continued trend towards higher power electric propulsion testing, VF-5 is planning for a reconfiguration to position the cryo-panels closer to the thruster and reduce the conductivity losses.

The Hypersonic Aerothermodynamics Particle (HAP) code was used to perform 3D Direct Simulation Monte Carlo (DSMC) simulations of facility pressure distributions. ${ }^{15}$ The simulations reported herein all assume a diffuse flow gas source with an annular geometry to represent cold xenon flow from a Hall thruster. The hot fire discharge plasma flow from an operating Hall thruster is not explicitly modeled here, though only minor differences have been noted for adding electro-static fields and/or charge exchange physics to DSMC flow simulations. ${ }^{16}$ The results of simulations for the two thruster locations and two cryo-panel configurations are provided in Fig. 9.

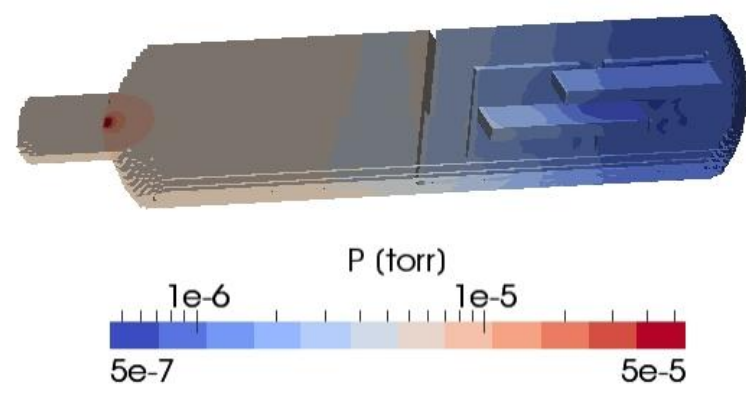

(a)

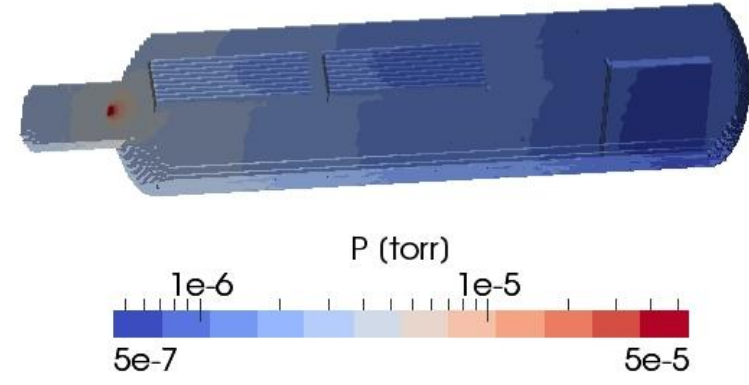

(c)

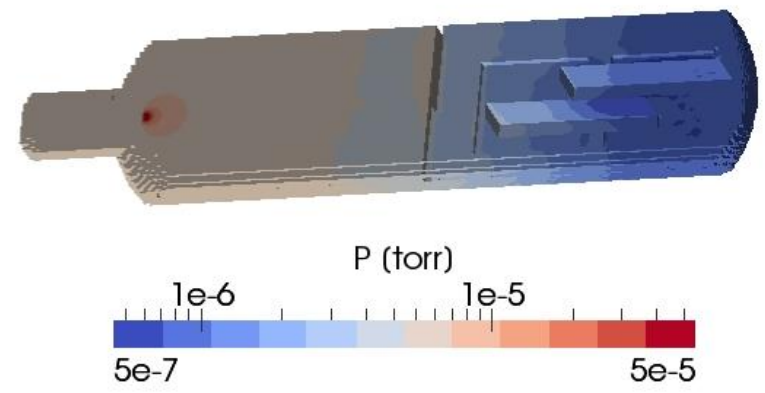

(b)

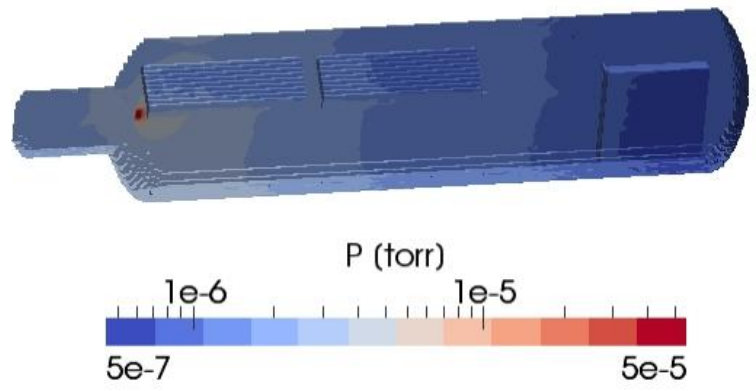

(d)

Figure 9. Facility pressure simulations for VF-5 with the thruster placed at the exit of the bell jar (a) and (c) and in the main chamber (b) and (d) current configuration (a) and (b) and after reconfiguration (c) and (d).

The results shown in Fig. 9 highlight the critical need for a standard in pressure measurements and a reference location to report the relevant pressures. By the today's standard reporting methods, all four test arrangements have quoted capability of 3,500,000 L/s of cryo-pumping and 250,000 L/s of ODP capability. Comparing figures 'a' to ' $b$ ' and ' $c$ ' to ' $d$ ', a pressure gauge placed downstream of the thruster would not only measure a significantly lower pressure than experienced by the thruster, but is also unable to differentiate the improved effective pumping speed 
by moving the thruster farther into the chamber. Finally, comparing figure ' $a$ ' to ' $c$ ' and ' $b$ ' to ' $d$ ', without any change to the typically reported pumping capability of the facility, only the internal facility conductance, the effective pumping speed is increased by a factor if three. Before the configuration change, the effective pumping speed of VF-5 with a thruster placed in the front of the bell jar is less than 300,0001/s (Xe). The configuration in figure 9-d will not meet, but start to approach the quoted performance.

\section{E. Gauge Location Recommendations}

The measurement of interest is the effective pumping speed observed at the thruster location. Ideally, this would be obtained with a pressure gauge located at the exit place of the thruster, reducing the calculations necessary to obtain the relevant data. However, using the methodology provided, a pressure reading from anywhere in the facility can be used to determine the relevant pressures and pumping speeds for a well characterized facility. Simulations can provide insight into the sensitivity of the gauge location to sources of uncertainty of transportable measurements.

1) Radial Distance from the Thruster

Several simulations were run to examine the pressure distribution in the radial direction along the thruster exit plane. Figure 10 displays the radial pressure distribution in VF-7 and VF-5 for several different thruster diameters with the same xenon flow rate. It can be seen in the simulation, that though the pressure near the thruster varies with the thruster geometry, as expected, but the pressure near the chamber wall is the same across the different cases. The results suggest that an appropriate measure of the background pressure can be made at the relatively uniform section near the chamber walls. The minimum radial distance the gauge should be located from the thruster is not dependent on the thruster radii, but rather chamber radii or some limit on absolute distance. Smaller diameter sources require more thruster radii because the absolute distance is shorter. These results indicate measurements

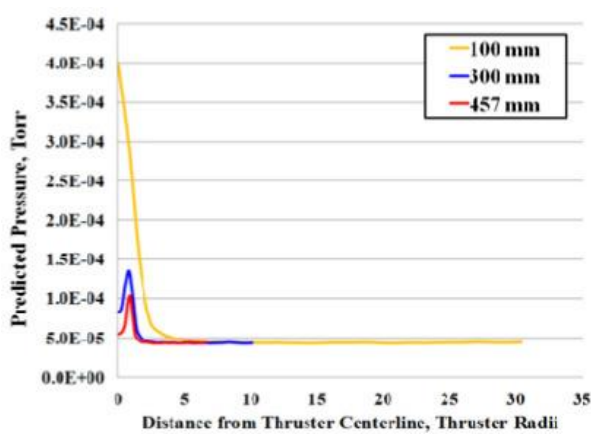

(a)

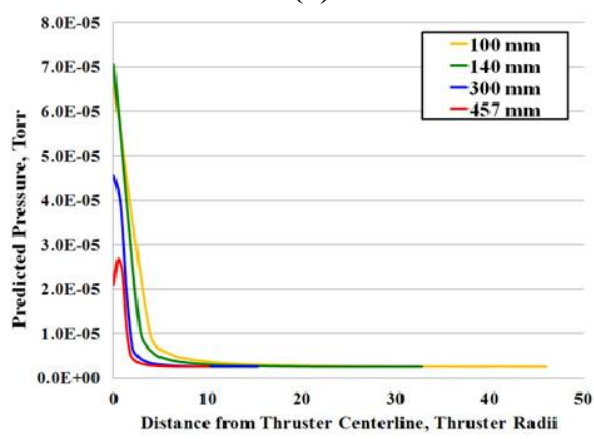

(d)

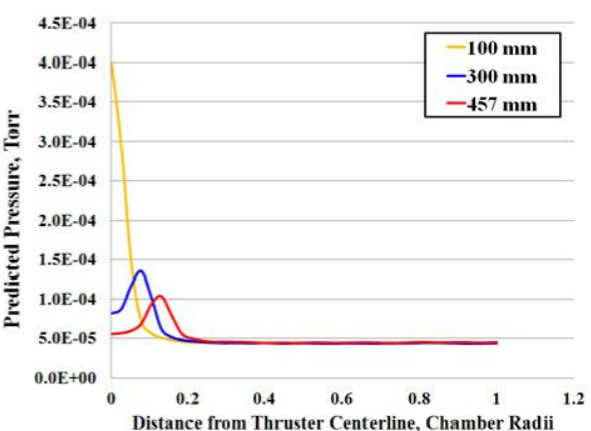

(b)

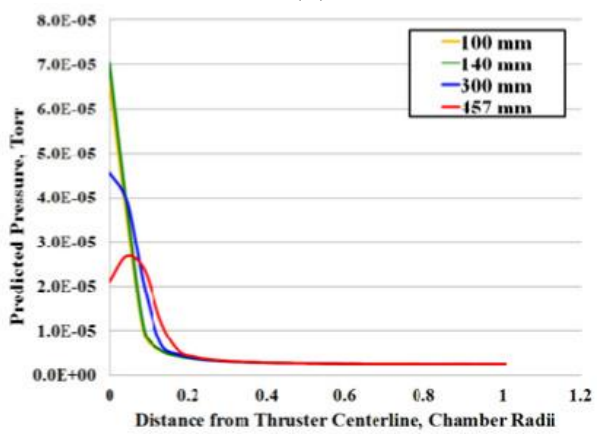

(e)

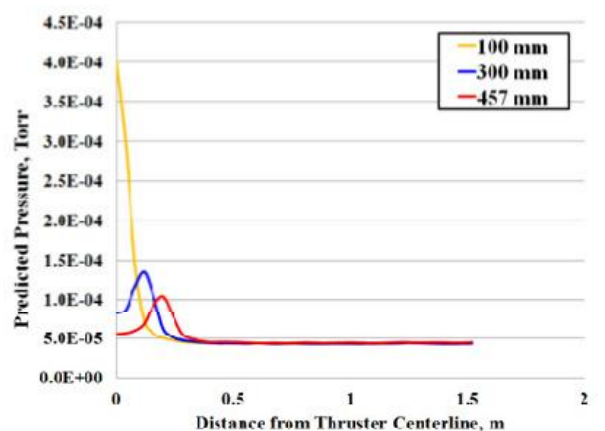

(c)

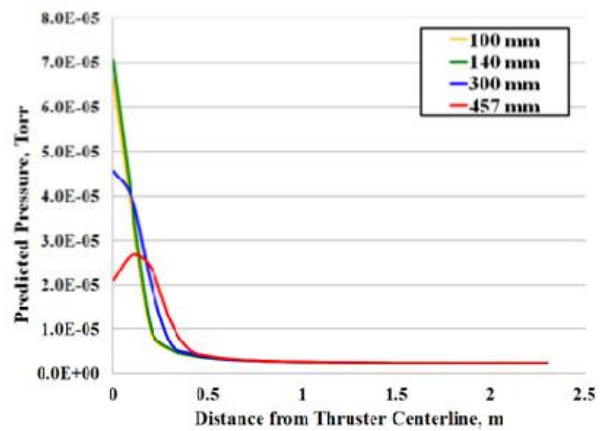

(f)

Figure 10. Pressure measurements in the radial direction to the thruster centerline for various geometries for VF-7 (top) and VF-5 (bottom).

should be made at least 0.6 chamber radii away from the centerline in the radial direction. It is also recommended that pressure measurements be made at least 1 meter from the outer diameter of the thruster when possible. Additional analyses will be completed for facilities with relatively small chamber radii relative to the thruster. 
2) Axial Distance from the Thruster

It may not always be possible to mount the pressure gauge(s) along the exit plane of the thruster, and it may also be desirable to have more than one gauge in an alternative location. The axial pressure distribution along the thruster centerline and the wall were also examined through simulation efforts. Figure 11 displays the axial distribution along the thruster centerline in VF-5 for the same flowrate, but different thruster geometries. Figure 11 illustrates that there is no axial pressure falloff dependency on thruster diameter. All cases assume the same flow-rate, but with different mass flux. Changing the total flow rate would have an effect on the magnitude of the pressure distribution; though the general shape of the profiles remain similar to those in Fig. 11. These results are in agreement with previous work which measured thruster plumes

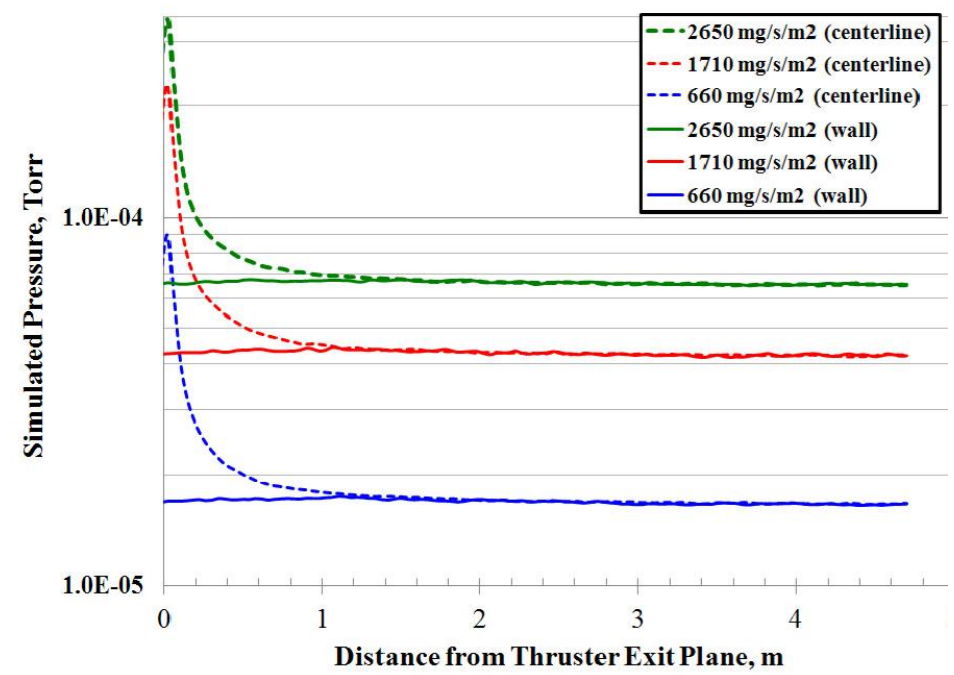

Figure 12. VF-7 axial pressure distribution along the wall and along the thruster centerline.

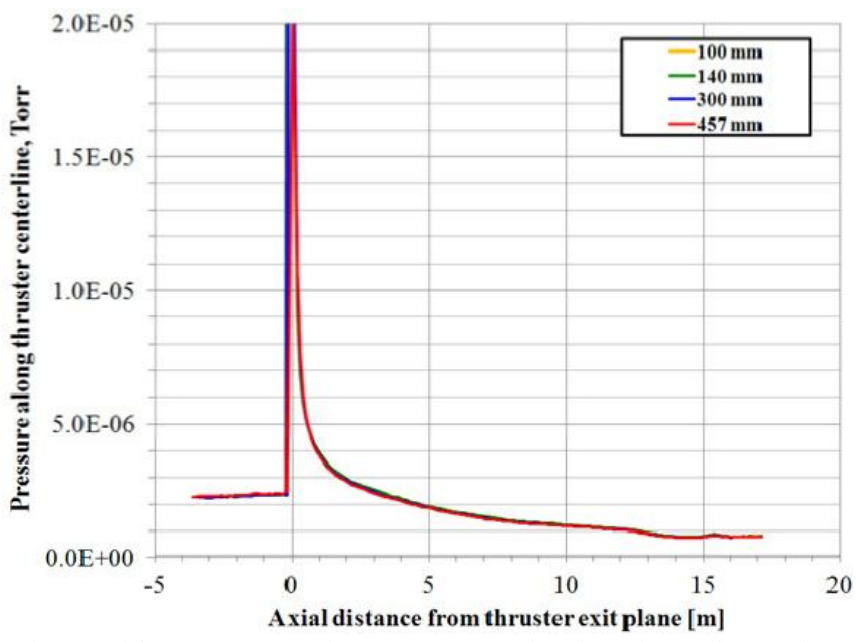

Figure 11. VF-5 axial pressure distribution of multiple diameter thrusters.

to expand to the background pressure by approximately $1.7 \mathrm{~m}$ downstream of the thruster exit plane. The simulation results also show a couple of meters downstream is sufficient distance to capture the background pressure along the thruster centerline. It is also notable that the region behind the thruster displays a fairly uniform pressure that corresponds to the near-wall pressure shown in the radial results. In general, it is also not recommended to place a pressure gauge in direct line of site of the plume. Figure 12 illustrates the pressure distribution of VF-7 both along the wall and along the centerline in the axial direction for three different flow rates. Figure 12 illustrates that at a distance of at least $2 \mathrm{~m}$ downstream of the thruster, for VF-7, the radial location does not impact the pressure reading and the two measurements should merge.

3) Distance Offset from the Wall

The authors' cold flow simulations, and both cold-flow and hot-flow testing have not shown any significant facility wall effect on pressure measurements. Our preliminary simulation results appear to show that a measurement made at the chamber wall would be sufficient. However, it should be noted that past work simulating facility effects have shown an accumulation of gas along the walls and "corners" of the chamber." Additional work and validation testing is required to provide a final recommendation on the minimum acceptable distance from the wall. The authors plan to measure pressures in the chamber corners of multiple facility geometries during near-term cold flow and hot-fire testing.

\section{F. Facility Effects Characterization (Simulating Higher Pressures)}

The results of electric propulsion testing are proven to be dependent on facility effects; most notably the facility background pressure and its impact on performance, plume measurements, and lifetime. Additionally, during system development and final spacecraft integration, testing may occur at various facilities under a range of conditions. A large cost of electric propulsion testing is in the test preparation, setup, diagnostics, etc. and adding a short facility effect characterization test to every performance and plume measurement test should have a minimal impact on the total cost. It is therefore recommended that all research and development testing include some level of facility effect characterization. For development hardware, the project should evaluate the various facilities and environments that the electric propulsion device will later be subjected. Flight hardware development may evaluate 
the risk and consider the conditions of the spacecraft integration testing required. For example, if the final integrated spacecraft will be tested at $5 \times 10^{-5}$ and the thruster development and performance characterization only occurred at $5 \times 10^{-6}$, it may be difficult to differentiate potential flight performance issues and detract from the value of the integrated test.

It is recommended to artificially increase the background pressure in the highest performing facilities for characterization of the potential variances that could be observed in lower capability facilities. Analysis should follow to determine what variations, if any, would be expected in flight. It is recommended that this be done through feeding gas directly into the pumps at known flow rates. This accumulation of data would provide significant insight to the community. The final implementation is still to be evaluated by the authors.

\section{Summary}

The community lacks a consistent methodology for making pressure readings and advertising facility pumping speed capabilities. Pumping speeds are advertised regardless of thruster position and internal conductance calculations. A defined standard for measurement methodology, system calibration, and uncertainty analysis is required. All electric propulsion test facilities should have some minimum characterization effort to allow transportability of measurements. It is recommended that pressure measurements be provided referenced to the exit plane of the thruster. Ideally the pressure gauge would be placed near the chamber wall at the exit plane. However, if additional gauges or alternative placement is desired, a methodology can be used to provide the background pressure and effective pumping speed at the relevant reference location. There has yet to be a recommendation regarding the minimum distance from the wall. Gauges placed downstream of the thruster within a $60^{\circ}$ half angle of the thruster should be located at least 2 meters downstream of the thruster. Gauges that may be in the presence of ions of an external source should have a neutralizer and the measurement impact of the neutralizer must be characterized. In all cases, the pressure reported should be at the exit plane of the thruster or sufficient information regarding the gauge location, gauge correction factors applied, and facility characterization must be provided to determine the pressure at the location of relevance. The pressure gauge hardware should be calibrated every six months with the controller, feedthroughs, cabling, etc. It is also recommended that the community include facility effect characterization during developmental testing whenever possible by artificially increasing the background pressure and evaluating potential impacts on performance, plume measurements, and life.

\section{Near-term Activities}

This task has significant remaining work until completion. The near-term tasks include validation of the model in multiple facilities, multiple configurations, and with cryo-pumping. The authors intend to perform additional testing at Glenn facilities VF-8, VF-5, and VF-12. Tests will be conducted with the source placed at various positions, hot-fire and cold flow data comparison, measurements made in facility "corners" during hot-fire testing, and an attempt to measure any wall effects. Remaining testing is expected to occur over the next several months, as many of the tests will be conducted during thruster testing supporting other projects. The authors also plan to evaluate various options to artificially increase the background pressure for facility effect characterization. The goal is to provide recommendations that can be implemented by all institutions performing electric propulsion testing while not overly constraining or cost prohibitive. Additional information on calibration and data uncertainty analysis is also required before submission for inclusion as a formal recommendation through the AIAA testing standardization committee.

\section{Acknowledgments}

The authors wish to thank David Byers for his insights, Mike Patterson for supporting this effort, Jonathan Burt for the HAP code and assistance in applying it for vacuum chamber simulations, and Dan Herman, Jon Vannord, and Hani Kamhawi for test support and fortuitous use of hardware as the validation continues. The work described in this paper was funded in part by the In-Space Propulsion Technology Program.

\section{References}

\footnotetext{
${ }^{1}$ Blott, R., Robinson, D., and Gabriel, S., "Verification - Electric Propulsion's Achilles Heel," IEPC-2011-061, 32 ${ }^{\text {nd }}$ International Electric Propulsion Conference, Wiesbaden, Germany, September 11-15, 2011.

${ }^{2}$ Blott, R., Gabriel, S., and Robinson, D., "Draft Handbook for Electric propulsion Verification by Test (Issue 0)," February $10,2012$.
} 
3 Byers, D., and Dankanich, J. W., “A Review of Facility Effects on Hall Effect Thrusters," IEPC-2009-076, 31 International Electric Propulsion Conference, Ann Arbor, MI, September 20-24, 2009.

${ }^{4}$ Randolph, T., Kim, V., Kaufman, H., Kozubsky, K., Zhurin, V., and Day, M., "Facility Effects in Stationary Plasma Thruster Testing," IEPC 1993-093, 23rd Int. Electric Propulsion Conference, 13-16 Sept. 1993, Seattle, WA, USA.

${ }^{5}$ Kahn, J., Zhurin, V., Kozubsky, K., Randolph, T., and Kim, V., "Effect of Background Nitrogen and Oxygen on Insulator Erosion in the SPT-100,' IEPC 1993-092, 23rd Int. Electric Propulsion Conference, 13-16 Sept. 1993, Seattle, WA, USA.

${ }^{6}$ Rawlin, V. K. and Mantenieks, M. A., Effect of Facility Background Gases on Internal Erosion of the 30-cm Hg Ion Thruster, AIAA 78-665, 13th AIAA/DGLR International Electric Propulsion Conference, April 25-27, 1978 San Diego, CA.

${ }^{7}$ Sengupta, A., Anderson, J. A., Garner, C., Brophy, J. R., deGroh, K. L., Banks, B. A., and Karniotis Thomas, T. A., "Deep Space 1 Flight Spare Ion Thruster 30,000 Hour Life Test," Journal of Propulsion and Power Vol. 25, No. 1, January - February 2009.

${ }^{8}$ Herman, D. A., Soulas, G. C., and Patterson, M. J., "Performance Characteristics of the NEXT Long-Duration Test after $16,550 \mathrm{~h}$ and $337 \mathrm{~kg}$ of Xenon Processed, AIAA 2008-4527, 44 ${ }^{\text {th }}$ AIAA Joint Propulsion Conference, Hartford, CT, July 21-23, 2008.

${ }^{9}$ deGrys, K., Mathers, A., Welander, B., and Khayms, V., "Demonstration of 10,400 Hours of Operation on a 4.5kW Qualification Model Hall Thruster," AIAA 2010-6698, 46 ${ }^{\text {th }}$ AIAA Joint Propulsion Conference, Nashville, TN, July 25-28, 2010.

${ }^{10}$ Arnold, P.C., and Borichevsky, S. C., "Journal of Vac. Sc. Technol. A 12, 568 (1994).

${ }^{11}$ Walker, M. L. R., Gallimore, A. D., Cai, C., and Boyd, I. D., "Pressure Map of a Facility as a Function of Flow Rate to Study Facility Effects," AIAA-2002-3815, 38 ${ }^{\text {th }}$ AIAA Joint Propulsion Conference, Indianapolis, IN, July 7-10, 2002.

${ }^{12}$ Walker, M. L. R., and Gallimore, A. "Neutral Density Map of Hall Thruster Plume Expansion in a Vacuum Chamber," Review of Scientific Instruments Vol. 76, 2005.

13 Fedchak, J. A., "Vacuum Standards and Calibrations," http://www.nist.gov/pml/div685/grp09/vacuumcalibrations.cfm, October 18, 2011.

${ }^{14}$ Camperchioli, B., "NASA Glenn Research Center Space Ground Test Facility \& Capabilities Chart,” October, 2011.

${ }^{15}$ Burt, J. M., Josyula, E., and Boyd, I. D., "Novel Cartesian Implementation of the Direct Simulation Monte Carlo Method," Journal of Thermophysics and Heat Transfer Vol. 26, No. 2, 2012.

${ }^{16}$ Boyd, I. D., Sun, Q., and Cai, C., "Particle Simulation of Hall Thruster Plumes in the 12V Vacuum Chamber," IEPC-2005138, $29^{\text {th }}$ International Electric Propulsion Conference, Oct. 31 - Nov 4, 2005, Princeton, NJ, USA. 